\title{
Moisture Diffusivity and Shrinkage of Fruit and Cladode of Opuntia ficus-indica during Infrared Drying
}

\author{
Amira Touil, ${ }^{1,2}$ Saber Chemkhi, ${ }^{1,3}$ and Fethi Zagrouba ${ }^{2}$ \\ ${ }^{1}$ Thermal Process Laboratory, Energy Technologies Research Center (CRTEn), Borj Cedria, BP 95 Hammam-Lif, Tunis 2050, Tunisia \\ ${ }^{2}$ Higher Institute of Environmental Sciences and Technologies, Carthage University, Tunisia \\ ${ }^{3}$ Chemical Engineering Department, Faculty of Engineering, King Khaled University, P.O. Box 394, Abha, Saudi Arabia
}

Correspondence should be addressed to Saber Chemkhi; saberchemkhi@yahoo.fr

Received 15 November 2013; Revised 10 February 2014; Accepted 24 February 2014; Published 3 April 2014

Academic Editor: Franco P. Pedreschi

Copyright (C) 2014 Amira Touil et al. This is an open access article distributed under the Creative Commons Attribution License, which permits unrestricted use, distribution, and reproduction in any medium, provided the original work is properly cited.

\begin{abstract}
Drying behaviour of prickly pear cladodes and fruits was studied with an Infrared dryer. The volume shrinkage for Opuntia ficusindica products is calculated and a linear relation was established to describe the experimental variation of shrinkage of the product versus its moisture content. Effective diffusion coefficient of moisture transfer was determined using the Fick law at three drying temperatures $\left(40,50\right.$, and $\left.60^{\circ} \mathrm{C}\right)$. Shrinkage was also included into the diffusion model for the determination of the effective diffusion coefficient. The obtained results of the effective moisture diffusivity, for the cladode and the fruit, were evaluated in the range of $1.77 \times 10^{-10}-5.07 \times 10^{-10} \mathrm{~m}^{2} / \mathrm{s}$ and $2.53 \times 10^{-10}-7.6 \times 10^{-10} \mathrm{~m}^{2} / \mathrm{s}$, respectively. The values of the activation energies for cladode and fruit were estimated to be 45.39 and $47.79 \mathrm{~kJ} / \mathrm{mol}$, respectively. However, these values of moisture diffusivity were estimated independently of the evolution of moisture content during drying process. Therefore, a correlation (full quadratic equation) for moisture diffusivity as a function of moisture content and temperature was developed. The parameters are obtained by a multilinear regression method. This equation was found satisfactory to describe the diffusivity evolution function of moisture content and temperature with correlation coefficients of 91.5 and $95 \%$.
\end{abstract}

\section{Introduction}

The Opuntia ficus-indica also named prickly pear is a xerophyte and a luscious plant. The consumption of prickly pear remains artisanal and the culture of the fruit and the cladode in view of industrial transformation remains insufficient. Recently, in some countries the prickly pear tree is cultivated for food industrial, medical, and cosmetic purposes [1]. Therefore, the use of dried fruits and cladodes increased with the increasing of their derivatives products, which urge the necessity of developing an efficient and effective method for the dehydrating of prickly pear fruits and cladodes.

Infrared (IR) radiation drying has been investigated as a potential method for obtaining high quality dried foodstuffs, including fruits, vegetables, and grains [2-6]. Infrared heating offers many advantages over conventional drying under similar drying conditions. These may include a reduced drying time, high energy efficiency, high quality finished products, uniform temperature in the product while drying, and a reduced necessity for air flow across the product [7]. Infrared drying has been recognized as a potential method for obtaining high quality dried foodstuffs. IR radiation energy is transferred from the heating element to the product surface without heating the surrounding air. The radiation impinges on the exposed material and penetrates it and then is converted to sensible heat [8].

The moisture migration process during drying is very complex and often involves one or more transport mechanisms such as liquid diffusion, vapour diffusion, surface diffusion, and hydrostatic pressure differences [9]. Drying rate increases as a result of equilibrium concentration of the water vapour on the surface of the materials at higher temperature. This produces a migration of moisture from the solid to the surface, which occurs through one or more mechanisms, namely, molecular diffusion, capillary flow, Knudsen flow, hydrodynamic flow, or surface diffusion. As a result, analysis of the mass transfer phenomenon is based on the assumption that effective moisture diffusivity represents 
all parameters influencing the process rate. In this context, many theoretical and experimental studies on the drying behaviour of different materials and the measurement of their moisture diffusivity in different drying conditions have been carried out $[6,10-16]$.

The difficulties of applying moisture diffusivity phenomena theory to food processes arise from the complex physical structure and composition of foods. One of the undesirable changes which occur simultaneously within moisture diffusion in drying process is the volume reduction or shrinkage, modifying physical properties and heat and mass exchange area and in particular affecting the diffusion coefficient of the materials. In general, shrinkage occurs as a result of volume reduction due to evaporation of the moisture contained in the solid. Heating and loss of water cause stresses in the cellular structure of the food and lead to changes in shape and decrease in dimensions [17]. Fruits and vegetables have high initial moisture contents (80-90\%) and suffer alterations to their original form during the drying process due to significant shrinkage.

The quantification of this phenomenon is important because it allows the analysis of the drying kinetics and consequently of the whole drying phenomenon. Another important parameter in drying is the moisture diffusivity which could be affected by shrinkage phenomenon. Its role is essential in simulation and optimization of the drying process, since water vapour transfer rate inside the materials is controlled by diffusion of moisture toward the outer surface [18] and then the water vapour concentration on the material outer surface decreases close to the equilibrium values. Thus any attempt to characterize the drying behaviour of the materials must inevitably address the physical parameters of the material such as shrinkage and moisture diffusivity. Since there are not much drying data for prickly pear in the literature $[19,20]$, we expect in this work to study the properties of shrinkage and moisture diffusivity of prickly pear fruits and cladodes during its drying using an Infrared dryer.

\section{Materials and Methods}

2.1. Biological Materials. The two products (prickly pear fruit and its cladode) were grown in the region of the Bouargoub, Tunisia. The samples were cut into small cubes (of $10 \mathrm{~mm}$ of side) for the cladode and into cylinders (of about $25 \mathrm{~mm}$ diameter and $5 \mathrm{~mm}$ of thickness) for the fruit.

2.2. Infrared Drying Experiments. We proceeded to determine the time evolution of the product water content by means of an Infrared humidity sensor (see Figure 1 and Table 1).

The drying experiments were carried out at three temperatures, that is, 40,50 , and $60^{\circ} \mathrm{C}$ drying temperatures. The amount of evaporated water during drying was determined directly from digital screen of drying equipment at about $0.5 \mathrm{~min}$ interval in each drying temperature. The experimental tests were replicated three times at each temperature and weight loss averages are reported.

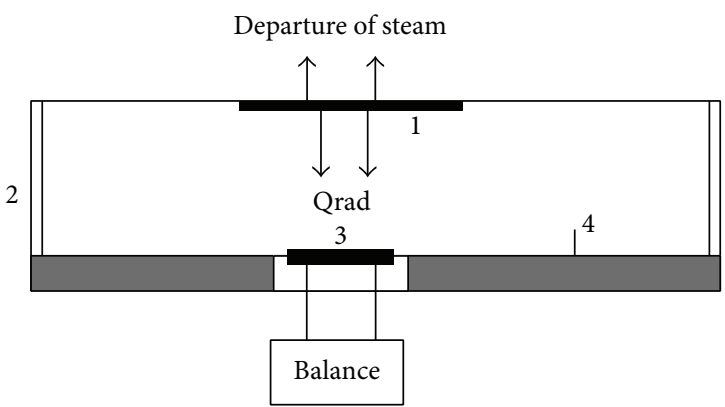
(1) Emitter Infrared
(4) Probe of temperature
(2) Glass window
Isolation + reflexion
(3) Sample

FIGURE 1: Scheme of the Infrared humidity sensor.

TABLE 1: Technical data of the Infrared dryer and moisture analyzer equipment.

\begin{tabular}{ll}
\hline Frequency: $50-60 \mathrm{~Hz}$ & Balance resolution: $1 \mathrm{mg}$ \\
$\begin{array}{l}\text { Power consumption }(\max ): \\
660 \mathrm{VA}\end{array}$ & Time switch (range): $0-300 \mathrm{~min}$ \\
Temperature range: $40-160^{\circ} \mathrm{C}$ & Graduation: $1^{\circ} \mathrm{C}$ \\
Reproducibility of the & Reproducibility (sample $=1 \mathrm{~g}):$ \\
temperature: $1 \%$ & $0.2 \%$ \\
\hline
\end{tabular}

2.3. Determination of Moisture Ratio. The moisture content $X$ (kg of water/kg of dry matter) was determined using the following equation:

$$
X=\frac{\left(w_{0}-w\right)-w_{1}}{w_{1}},
$$

where $w_{0}$ is the initial weight of sample, $w$ is the amount of evaporated water, and $w_{1}$ is the sample dry matter mass. The moisture ratio (MR) was defined as follows:

$$
\operatorname{MR}=\frac{\left(X-X_{e}\right)}{\left(X_{0}-X_{e}\right)},
$$

where $X_{e}$ is the equilibrium moisture content and $X_{0}$ is the initial moisture content.

2.4. Shrinkage and Apparent Density. Shrinkage of foodstuff during drying is unavoidable because heating and removal of water from the food matrix may cause stresses in the cellular structure, hence leading to structural collapse, changes in volume, shape deformation, and capillaries contraction [17]. Ideally, it can be considered that the shrinkage of the material is equal to the volume of the removed water. Therefore, a parametric relationship can be obtained which relates the volume shrinkage to the moisture content of the material.

The equilibrium relation between the apparent density of the product and its moisture content was investigated by means of an apparatus based on Archimedes's law. The volume of the sample is determined by measuring the difference in weight of that sample above and under water. 
The sample is coated with paraffin to prevent the uptake of water. The specific volume was calculated by the following linear equation:

$$
v=v_{0}(1+\beta X),
$$

where $\beta$ is the shrinkage coefficient, $v$ is the specific volume at material moisture content $X$, and $v_{0}$ is the specific volume of the dry material.

2.5. Effective Moisture Diffusivity. The term effective diffusivity $\left(D_{\text {eff }}\right)$ is defined to describe the rate of moisture movement, no matter which mechanism is involved. A complete drying profile consists of the first stage of drying, a constant-rate period, and a falling-rate period. In most applications the dominating stage is the third period [21]. It is frequently agreed that the mechanism of moisture movement within a hygroscopic solid during the falling-rate period could be represented by a diffusion phenomenon according to Fick's second law. The one-dimensional diffusion is a good approximation for most practical systems. Thus, the unsteady state diffusion of moisture by Fick's second law can be expressed as

$$
\frac{\partial X}{\partial t}=\nabla \cdot\left(D_{\mathrm{eff}} \nabla X\right),
$$

where $X$ is the moisture content ( $\mathrm{kg}$ water $/ \mathrm{kg}$ dry matter), $t$ is the drying time, and $D_{\text {eff }}$ is the effective diffusivity $\left(\mathrm{m}^{2} / \mathrm{s}\right)$.

In order to solve this partial differential equation, it is assumed that

(i) the initial moisture content is uniform throughout the material,

(ii) there is a thermal equilibrium between the material surface and the drying air,

(iii) the material shape remains uniform during the drying.

The general solution of (4) can be derived for various standard geometries (cube for the cladode (5) and cylinder for the fruit (6)) using appropriate boundary conditions [22]:

$$
\begin{gathered}
\mathrm{MR}=\frac{X_{t}-X_{e}}{X_{0}-X_{e}}=\frac{8}{\pi^{2}} \sum_{n=1}^{\infty} \frac{1}{(2 n-1)^{2}} \exp \left(-(2 n-1)^{2} \frac{\pi^{2} D_{\mathrm{eff}} t}{L^{2}}\right), \\
\mathrm{MR}=\frac{X_{t}-X_{e}}{X_{0}-X_{e}}=\sum_{n=1}^{\infty} \frac{1}{\varepsilon_{n}^{2}} \exp \left(-\frac{\varepsilon_{n}^{2} D_{\mathrm{eft}} t}{r_{c}^{2}}\right)
\end{gathered}
$$

where $\varepsilon_{n}$ is roots of Bessel function.

In many cases the effective diffusivity is estimated by using only the first term of the general solution [23]. Thus, (5) and (6) can be written as in (7) and (8), respectively:

$$
\begin{gathered}
\mathrm{MR}=\frac{X_{t}-X_{e}}{X_{0}-X_{e}}=\frac{8}{\pi^{2}} \exp \left(-\frac{\pi^{2} D_{\mathrm{eff}} t}{L^{2}}\right), \\
\mathrm{MR}=\frac{X_{t}-X_{e}}{X_{0}-X_{e}}=\frac{4}{\varepsilon_{1}^{2}} \exp \left(-\frac{\varepsilon_{1}^{2} D_{\mathrm{eff}} t}{r_{c}^{2}}\right) .
\end{gathered}
$$

A general form of (7) and (8) can be written in logarithmic form as in

$$
\ln (\mathrm{MR})=A-B * t,
$$

where constant B is $\pi^{2} D_{\text {eff }} / L^{2}$ for a cube and $\varepsilon_{1}^{2} D_{\text {eff }} / r_{c}^{2}$ for a cylinder.

The variation of the effective diffusivity of the water with temperature is classically represented by an Arrhenius type equation:

$$
D_{\text {eff }}=D_{0} \exp \left(-\frac{E_{a}}{R T}\right) .
$$

The activation energy $E_{a}$ can be determined from the plot of $\ln \left(D_{\text {eff }}\right)$ versus $1 / T$. The slope of the line is $\left(E_{a} / R\right)$ and the intercept equals $\ln \left(D_{0}\right)$ [24].

2.6. Equilibrium Moisture Content. In the sorption isotherms, the equilibrium moisture content of the prickly pear was determined at $40,50,60$, and $70^{\circ} \mathrm{C}$. The static method was applied. This method is based on the use of sulfuric acid to maintain a fixed relative humidity in a range of $5-95 \%$. The equilibrium moisture content $\left(X_{e}\right)$ of the samples in the air dryer, necessary for the calculation of effective diffusivity values, was determined as a function of temperature and relative humidity of air drying from estimated sorption isotherms of fruit and cladode of prickly pear using the GAB model with this general equation [25]:

$$
X_{e}=\frac{X_{m} C K a_{w}}{\left(1-K a_{w}\right)\left(1-K a_{w}+C K a_{w}\right)},
$$

where $a_{w}$ is the moisture activity, $K$ is the difference of activation energy in multilayers $(\mathrm{J} / \mathrm{mol}), C$ is the energy excess $(\mathrm{J} / \mathrm{mol})$, and $X_{m}$ is the absorbed moisture content in multilayer's form (dry basis).

2.7. Statistical Analysis. Regression analyses were done by using the computer program "CurvExpert Professional 1.5." The performance of the model was evaluated using various statistical parameters such as the correlation coefficient $\left(R^{2}\right)$ and the standard error $(S)$.

\section{Results and Discussion}

3.1. Drying Curves. In order to consider drying behaviour, different drying curves of a hygroscopic product may be plotted like rate of drying versus moisture content. Figure 2 shows the variations of moisture content of the drying samples against time for different temperatures and for the cases of fruit and cladode of prickly pear. The results indicate that the temperature increasing opposed to the moisture content.

Examination of these figures shows that the drying occurred during two periods which are almost straight lines, regardless of drying conditions. This is also obvious from Figure 3 in which the rate of drying is plotted against moisture ratio. These indicate that since the moisture content of 


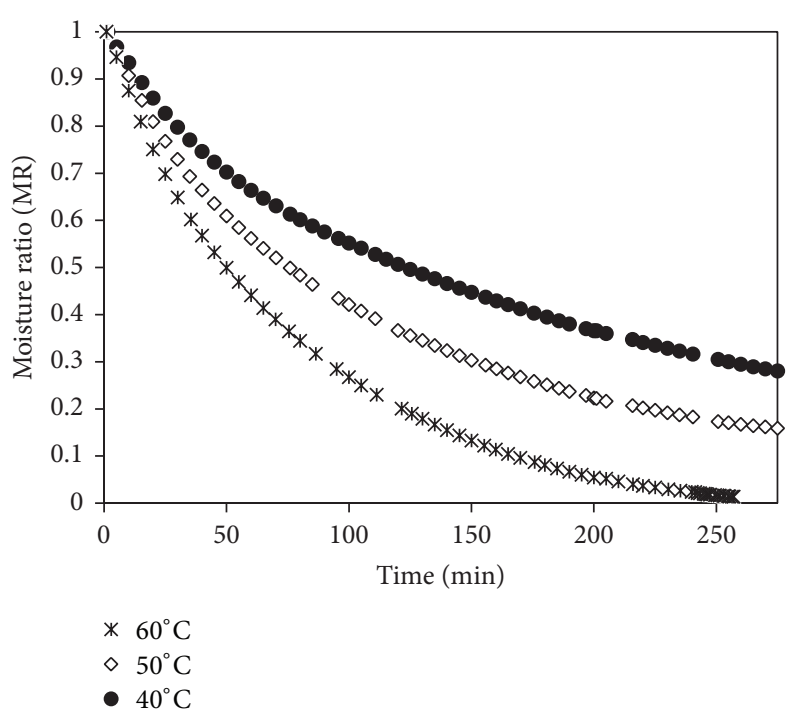

(a)

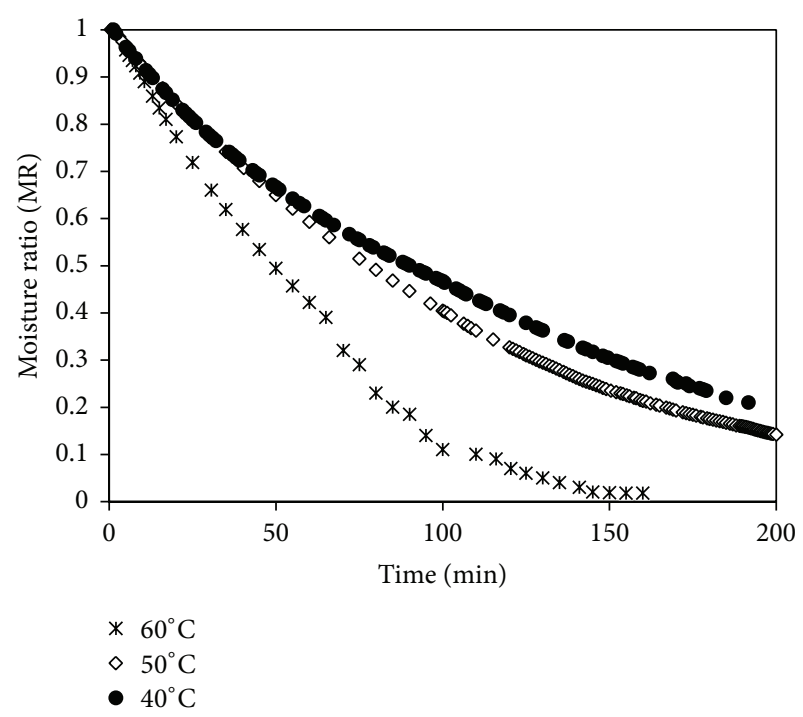

(b)

FIGURE 2: Moisture ratio versus time at different temperatures for the cladode (a) and the prickly pear fruit (b).

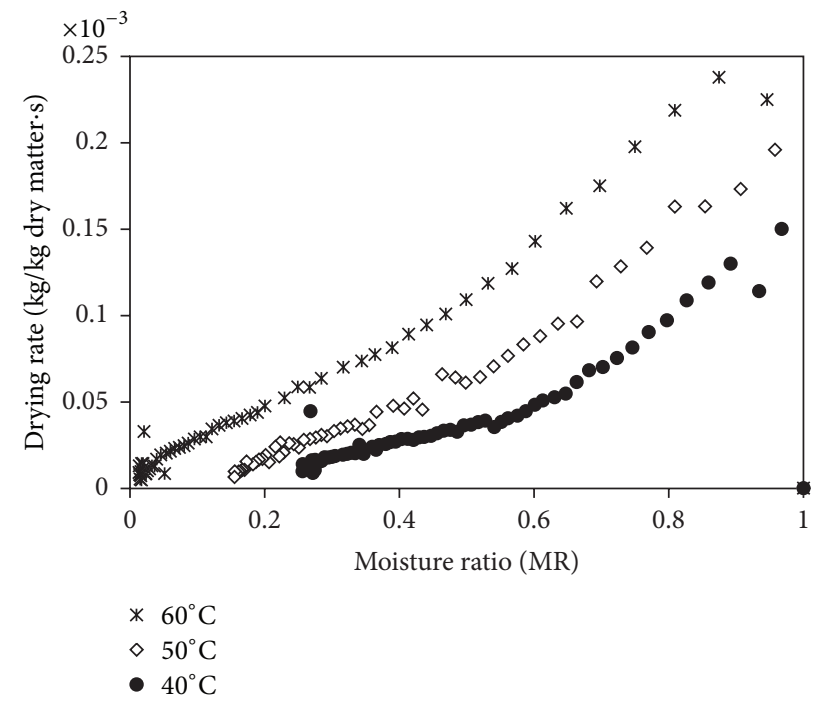

(a)

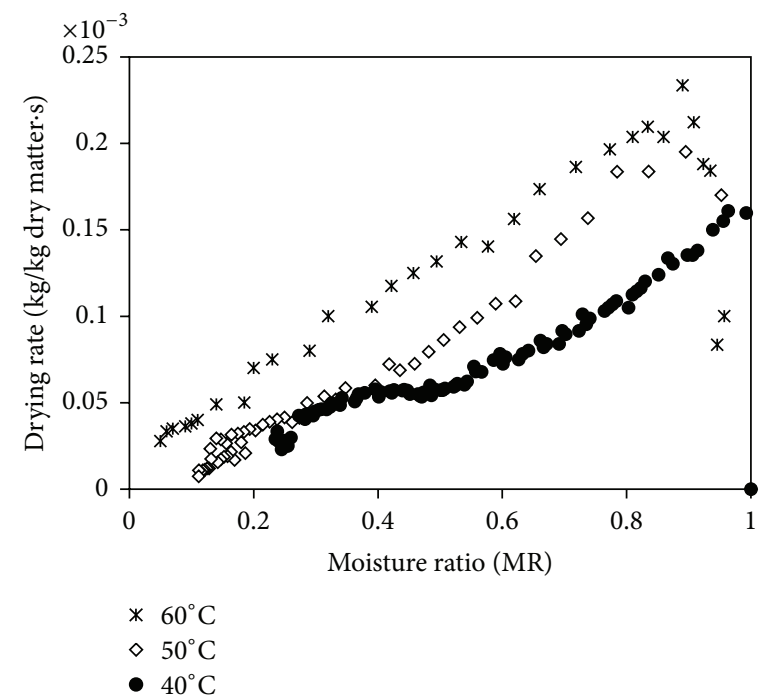

(b)

FIGURE 3: Rate of drying versus moisture ratio for different temperatures for the cladode (a) and the prickly pear fruit (b).

product is low, a constant rate period would not be expected and, therefore, drying takes place under first and second falling rate periods [26]. During these periods of drying the movement of liquid water to the surface could take place through different mechanisms and so surface diffusion is insufficient to maintain a continuous film covering the entire area and the surface remains unsaturated. During these periods resistance to the mass transfer at the surface is negligible compared to internal resistance of the sample and rate of moisture migration is controlled by diffusion.

3.2. Desorption Isotherms. In Table 2, the results of the $\mathrm{GAB}$ model applied to describe desorption isotherms of the fruit and the cladode of prickly pears are presented. Three temperatures $\left(40,50\right.$, and $\left.60^{\circ} \mathrm{C}\right)$ are employed. We remark that we have a high correlation coefficient superior to $99 \%$ and a standard error inferior to 0.01 . The results agree with published papers that use the GAB model $[20,25]$.

3.3. Shrinkage Factor. Figure 4 shows the experimental variation of the specific volume versus the average moisture content of prickly pear fruit and cladode. The specific volume varies linearly versus prickly pear moisture content. This linear evolution corresponds to a total shrinkage (see (3)), which means that the volume loss is equal to the volume of removed moisture. Similar results are found for carrot [27], 
TABLE 2: GAB model parameters for prickly pears at three temperatures [20].

\begin{tabular}{lcccccc}
\hline & \multicolumn{3}{c}{ Fruit } & \multicolumn{3}{c}{ Cladode } \\
& $40^{\circ} \mathrm{C}$ & $50^{\circ} \mathrm{C}$ & $60^{\circ} \mathrm{C}$ & $40^{\circ} \mathrm{C}$ & $50^{\circ} \mathrm{C}$ & $60^{\circ} \mathrm{C}$ \\
\hline$K$ & 0.924 & 0.865 & 0.865 & 0.960 & 0.908 & 0.904 \\
$C$ & 193.02 & 100.71 & 889 & 67.766 & 12.069 & 16.662 \\
$X_{m}$ & 0.070 & 0.064 & 0.057 & 0.057 & 0.062 & 0.057 \\
Statistical & & & & & & \\
parameters & & & & & & \\
$\quad R^{2}$ & 0.9999 & 0.9966 & 0.9978 & 0.9987 & 0.9982 & 0.9992 \\
$\quad S$ & 0.003 & 0.001 & 0.009 & 0.014 & 0.011 & 0.006 \\
\hline
\end{tabular}

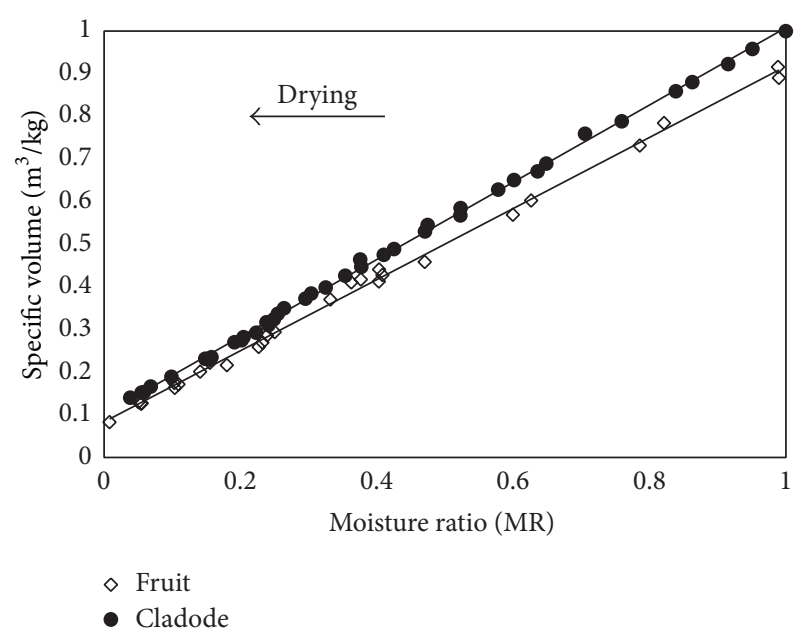

FIGURE 4: Specific volume evolution versus moisture ratio of prickly pear fruit and cladode.

banana [28], and potato [25]. The shrinkage coefficients, $\beta$, determined from the slope (Figure 4), were about 1.268 and 1.393 for cladode and fruit, respectively.

3.4. Effective Moisture Diffusivity and Volume Shrinkage. The effective diffusivity of the material is affected due to the shorter distance that moisture needs to travel before the evaporation to the surroundings. Published results have indicated better estimation in the diffusivity values by taking into account the shrinkage effect during drying [29]. Figure 5 shows a typical plot presenting a comparison between two calculation methods, without considering shrinkage of material, for the determination of the moisture diffusivity and by taking into account the shrinkage of the product.

Moisture gradient occurring inside the food during drying generates stresses in the cellular structure of the food resulting in the structure collapse which responds to the physical changes of shape and dimension or the volume change of material [17]. Such cell wall disruption subsequently affects the diffusing distance of moisture which moves from inside to the outside. Thus, this factor must be included into the mathematical model in order to predict accurately the sample moisture content during drying or to determine the correct effective diffusion coefficient.

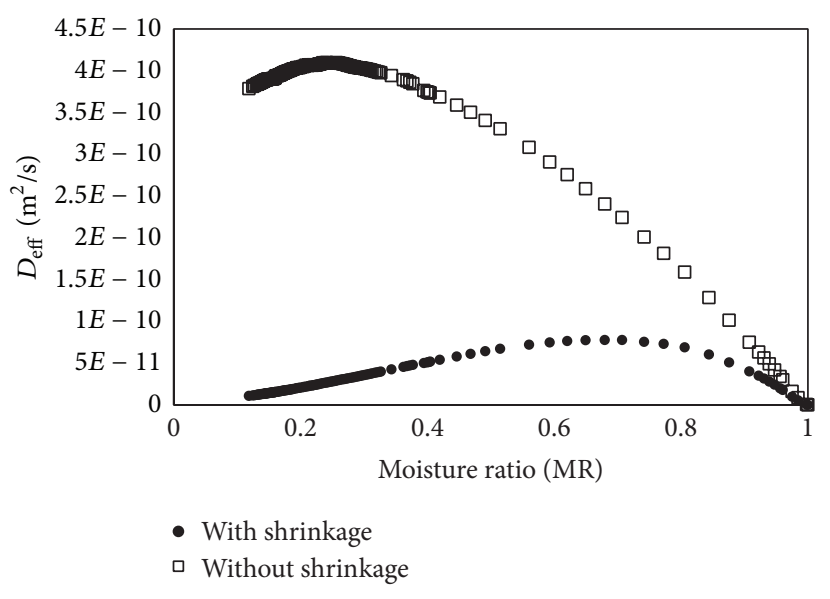

FIGURE 5: Effective moisture diffusivity evolution with a moisture ratio of fruit during IR drying at $50^{\circ} \mathrm{C}$ (with and without considering the shrinkage).

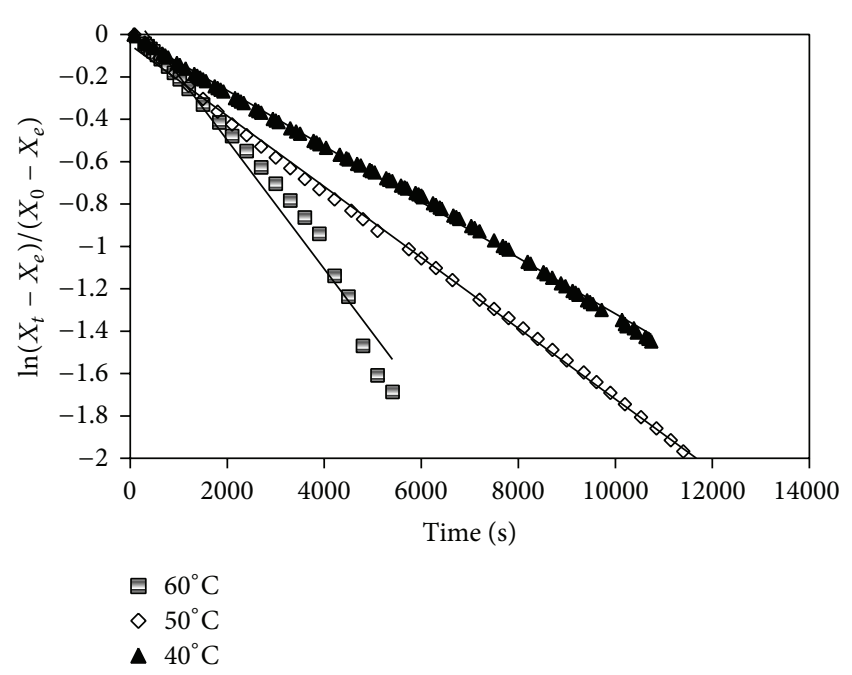

FIgURE 6: Variations of $\ln (\mathrm{MR})$ with time at different temperatures for prickly pear fruit.

3.5. Estimation of Effective Moisture Diffusivity. In Figures 6 and 7 by using experimental drying data, the logarithm of moisture ratio (MR) is plotted against time for different air temperatures and in each case the moisture diffusivity is estimated by using the slopes derived from the linear regression of the $\ln (\mathrm{MR})$ against time.

The variations of $\ln \left(D_{\text {eff }}\right)$ versus $(1 / T)$ for prickly pear fruit and cladode are shown in Figure 8. Analysis of the experimental data revealed the existence of linear relationships between these parameters. Correlation coefficients $\left(R^{2}\right)$ of the fitted lines with experimental data are obtained as 0.9826 and 0.9602 for fruit and cladode, respectively. The values of activation energies for fruit and cladode are obtained as 47.79 and $45.39 \mathrm{~kJ} / \mathrm{mol}$, respectively (Table 3 ).

However, this method only assumes a constant diffusion coefficient throughout the whole drying process and it can be related to product temperature via the Arrhenius equation. In 


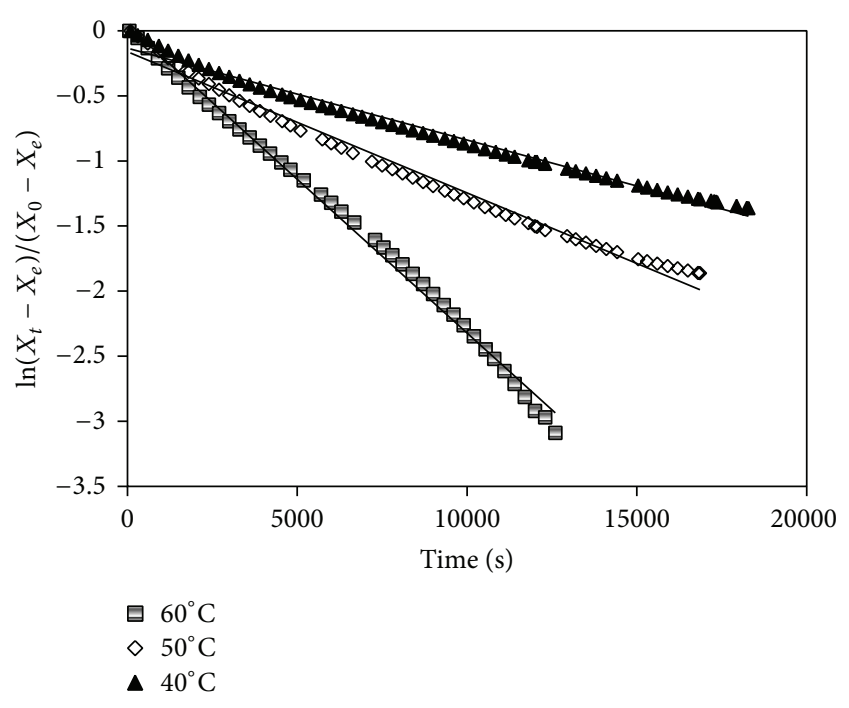

FIGURE 7: Variations of $\ln (\mathrm{MR})$ with time at different temperatures for prickly pear cladode.

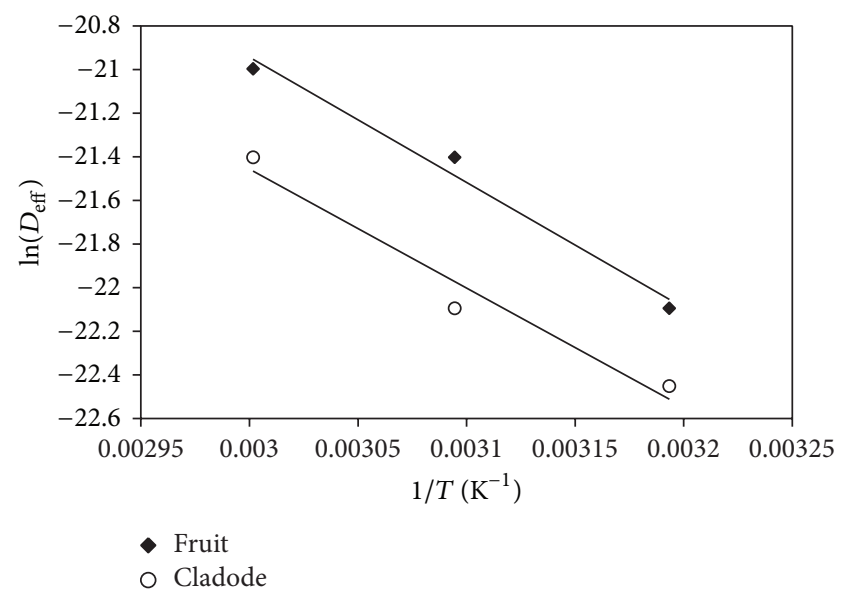

FIGURE 8: Variations of logarithms of moisture diffusivity with $(1 / T)$ for fruit and cladode.

TABle 3: Parameters of the effective diffusivity and the activation energy for prickly pear.

\begin{tabular}{lccc}
\hline & $E_{a}(\mathrm{KJ} / \mathrm{mol})$ & $D_{0}\left(\mathrm{~m}^{2} / \mathrm{s}\right)$ & $R^{2}$ \\
\hline Fruit & 47.79 & 0.02445 & 0.9826 \\
Cladode & 45.39 & 0.00617 & 0.9602 \\
\hline
\end{tabular}

reality, the diffusion coefficient is rarely constant but varies with moisture content, temperature, and spatial coordinate.

3.6. Modelling of the Effective Diffusivity. It can be seen from Figures 9 and 10 that effective diffusivity increases with temperature but varying trends are observed with respect to moisture content. At high temperature the water molecules are loosely bound to the food matrix, thus requiring less energy to remove than at lower temperature [30]. In contrast, the dependency of moisture content is a function of the

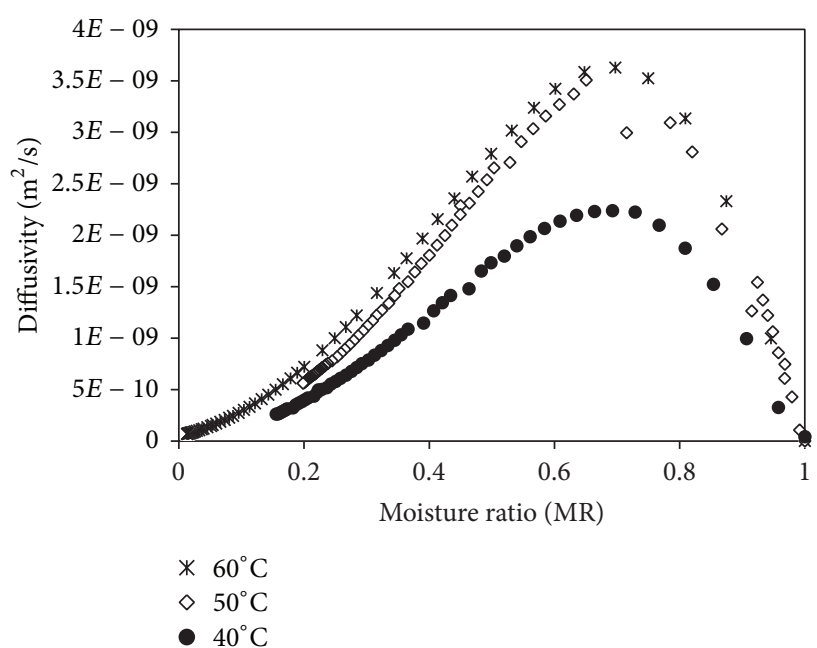

FIGURE 9: Variation of effective diffusivity of cladode with moisture content at different drying temperatures.

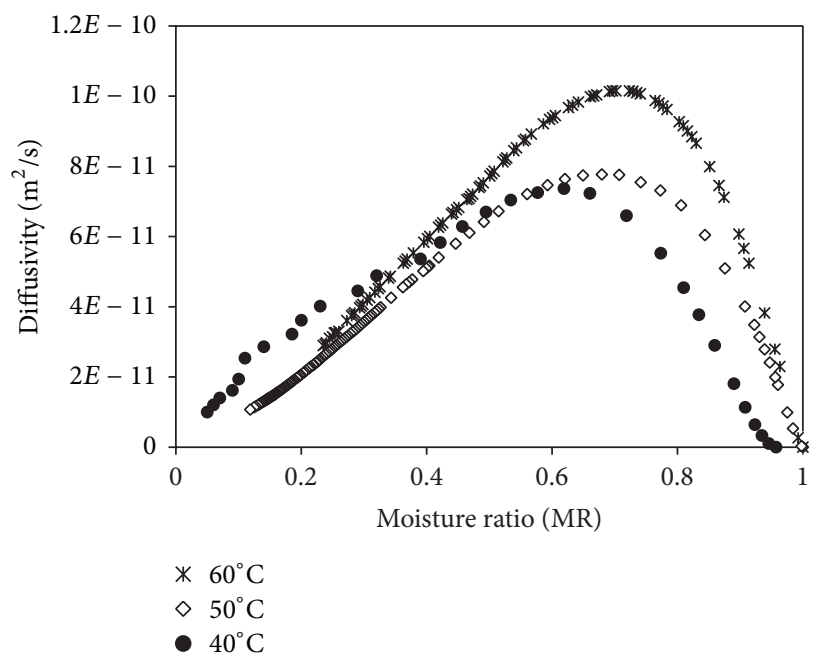

FIGURE 10: Variation of effective diffusivity of fruit with moisture content at different drying temperatures.

structure of the food product and void fraction has been known to affect diffusivity significantly.

During isothermal drying, as shown in Figures 9 and 10, the effective diffusivity calculated using the Fick model considering the shrinkage factor increases in the beginning of the drying in the first falling rate period and when the drying entered into the second period, the diffusivity changed slightly with moisture content. This behaviour of the moisture diffusivity might be the result of the changing mechanism during drying: in the first stage of drying, diffusion of liquid water might be the main mass transfer mechanism. Then, the vapour diffusion of water may be predominant as the drying progresses.

Various empirical models relating to effective diffusivity as a function of temperature and moisture content have been compiled and reported by the authors. 
TABLE 4: Effective diffusion coefficient parameters simulated by a full quadratic model.

\begin{tabular}{lccccccc}
\hline & & \multicolumn{4}{c}{ Coefficient parameters } & \multicolumn{3}{c}{ Statistical parameters } \\
& $a$ & $b$ & $c$ & $d$ & $e$ & $f$ & $R^{2}$ \\
\hline Fruit & $7.56010^{-9}$ & $2.15010^{-9}$ & $-4.94410^{-11}$ & $-3.36410^{-10}$ & $8.01910^{-14}$ & $-5.45610^{-12}$ & 0.9508 \\
Cladode & $5.91510^{-7}$ & $5.77110^{-8}$ & $-3.76210^{-9}$ & $-9.73210^{-9}$ & $5.95810^{-12}$ & $-1.40110^{-10}$ & 0.9150 \\
\hline
\end{tabular}

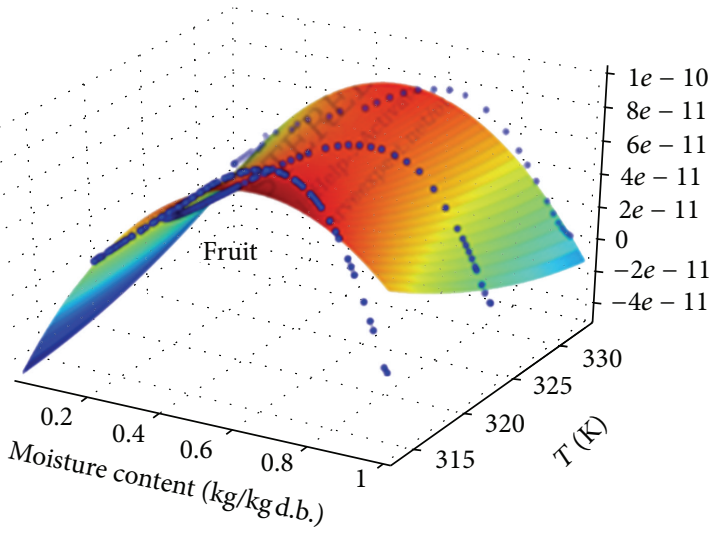

(a)

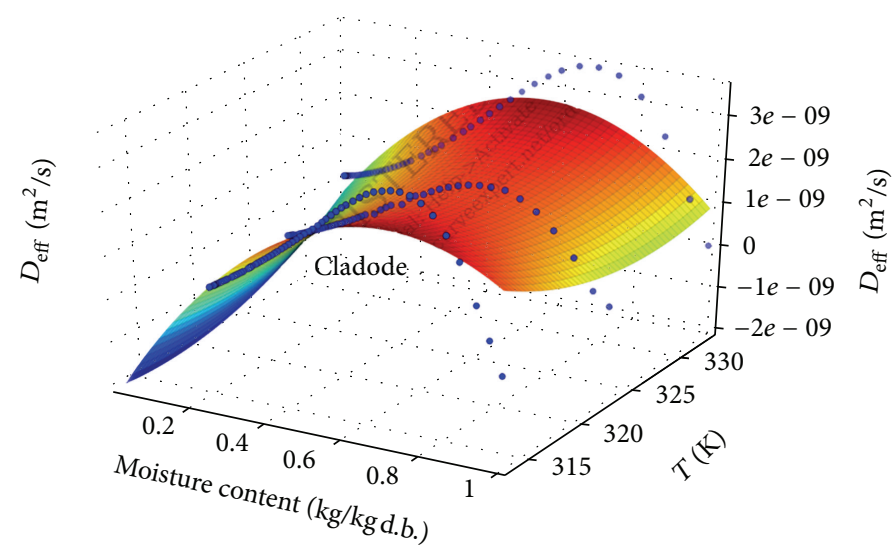

(b)

FIGURE 11: Comparison between experimental and simulated effective moisture diffusivity of fruit (a) and cladode (b).

An Arrhenius type correlation proposed by Azzouz et al. [31] as in (12) is assumed for effective moisture diffusivity:

$$
D_{\text {eff }}=D_{0} \exp \left(-\frac{E_{a}}{R T}\right) \exp [-(C T+D) X] .
$$

Chemkhi and Zagrouba [32] reported that the moisture transfer coefficient of clay material depends principally on the moisture content of the product and the drying air temperature. They were modelling the effective diffusivities using polynomial model for each temperature:

$$
D_{\text {eff }}(T)=a X^{2}+b X+c .
$$

In this work in order to consider the effect of both temperature and moisture content on moisture diffusivity, we proposed a full quadratic equation (see (14)):

$$
D_{\text {eff }}=a+b \cdot X+c \cdot T+d \cdot X^{2}+e \cdot T^{2}+f(X \cdot T) .
$$

The modelling results are presented in Table 4 and the simulated curves were presented in Figure 11.

\section{Conclusion}

The values of shrinkage for prickly pear fruit and cladode during Infrared drying are calculated and a linear relation was determined to describe the experimental variation of shrinkage of the product versus its moisture content. This shrinkage was also included into the diffusion model for determining the effective diffusion coefficient. The values of the effective moisture diffusivity which were obtained for the cladode and the fruit are in the range of $1.77 \times$ $10^{-10}-5.071 \times 10^{-10} \mathrm{~m}^{2} / \mathrm{s}$ and $2.53 \times 10^{-10}-7.6 \times 10^{-10} \mathrm{~m}^{2} / \mathrm{s}$, respectively. Correlations in which moisture diffusivity can be related to product temperature via the Arrhenius equation are developed. The values of activation energies for cladode and fruit are obtained as 45.39 and $47.79 \mathrm{~kJ} / \mathrm{mol}$, respectively. However, this numerical method for the estimation of the effective diffusion coefficient only assumes a constant diffusion coefficient throughout the whole drying process. For this reason, we proposed to correlate moisture content and temperature in a full quadratic equation which their parameters are obtained by a multilinear regression method. This relation was found satisfactory to describe the diffusivity evolution function of moisture content and temperature with correlation coefficients of 91.5 and $95 \%$.

\section{Nomenclature}

$a_{w}:$ Moisture activity

C: $\quad$ Energy excess $(\mathrm{J} / \mathrm{mol})$

$D_{\text {eff: }}$ Effective diffusivity $\left(\mathrm{m}^{2} / \mathrm{s}\right)$

$D_{0}$ : Arrhenius factor $\left(\mathrm{m}^{2} / \mathrm{s}\right)$

$E_{a}:$ Activation energy $(\mathrm{kJ} / \mathrm{mol})$

IR: Infrared

$K$ : Difference of activation energy in multilayers $(\mathrm{J} / \mathrm{mol})$

L: $\quad$ Thickness of the slab (m)

MR: Moisture ratio

$R: \quad$ Ideal gas constant $(\mathrm{kJ} / \mathrm{mol} \mathrm{K})$

$R^{2}$ : Correlation coefficient

$r_{c}:$ Radius of the cylinder $(\mathrm{m})$

$S: \quad$ Standard error

T: $\quad$ Temperature (K)

$t$ : Drying time (s) 
$v: \quad$ Specific volume $\left(\mathrm{m}^{3} / \mathrm{kg}\right)$

$v_{0}$ : Specific volume of dry material $\left(\mathrm{m}^{3} / \mathrm{kg}\right)$

$w$ : Amount of evaporated water $(\mathrm{kg})$

$w_{0}$ : Initial weight of sample $(\mathrm{kg})$

$w_{1}$ : Sample dry matter mass $(\mathrm{kg})$

$X$ : Moisture content $(\mathrm{kg} / \mathrm{kg}$ dry basis)

$X_{e}:$ Equilibrium moisture content $(\mathrm{kg} / \mathrm{kg}$ dry basis)

$X_{0}$ : Initial moisture content $(\mathrm{kg} / \mathrm{kg}$ dry basis)

$X_{m}$ : Absorbed moisture content in multilayer's form ( $\mathrm{kg} / \mathrm{kg}$ dry basis).

\section{Greek Letters}

$\beta$ : Shrinkage coefficient

$\varepsilon_{n}$ : Roots of Bessel function.

\section{Conflict of Interests}

The authors declare that there is no conflict of interests regarding the publication of this paper.

\section{References}

[1] A. Kaanane, "Techniques de valorisation industrielle des figues de Barbarie. In: Le cactus (l'Opuntia à fruit comestible) appelé communément Figuier de Barbarie," Acte de la deuxième journée nationale sur la culture du cactus. El Kalaa des Sragna. Maroc, pp. 13-14, 2000.

[2] T. Abe and T. M. Afzal, "Thin-layer infrared radiation drying of rough rice," Journal of Agricultural Engineering Research, vol. 67, no. 4 , pp. $289-297,1997$.

[3] T. M. Afzal and T. Abe, "Diffusion in potato during far infrared radiation drying," Journal of Food Engineering, vol. 37, no. 4, pp. 353-365, 1998.

[4] H. Umesh Hebbar and N. K. Rastogi, "Mass transfer during infrared drying of cashew kernel," Journal of Food Engineering, vol. 47, no. 1, pp. 1-5, 2001.

[5] K. Zhu, J. Zou, Z. Chu, and X. Li, "Heat and mass transfer of seed drying in a two-pass infrared radiation vibrated bed," Heat Transfer-Asian Research, vol. 31, no. 2, pp. 141-147, 2002.

[6] A. Cağlar, I. T. Toğrul, and H. Toğrul, "Moisture and thermal diffusivity of seedless grape under infrared drying," Food and Bioproducts Processing, vol. 87, pp. 292-300, 2009.

[7] G. P. Sharma, R. C. Verma, and P. B. Pathare, "Thin-layer infrared radiation drying of onion slices," Journal of Food Engineering, vol. 67, no. 3, pp. 361-366, 2005.

[8] A. S. Ginzburg, Application of Infrared Radiation in Food Processing, Leonard Hill, London, UK, 1969.

[9] A. S. Mujumdar and S. Devahastin, "Fundamental principles of drying," in Guide to Industrial Drying, A. S. Mujumdar, Ed., Hyderabad, India, 2008.

[10] M. S. Hatamipour and D. Mowla, "Correlations for shrinkage, density and diffusivity for drying of maize and green peas in a fluidized bed with energy carrier," Journal of Food Engineering, vol. 59, no. 2-3, pp. 221-227, 2003.

[11] I. Doymaz, "Convective air drying characteristics of thin layer carrots," Journal of Food Engineering, vol. 61, no. 3, pp. 359-364, 2004.
[12] G. P. Sharma and S. Prasad, "Effective moisture diffusivity of garlic cloves undergoing microwave-convective drying," Journal of Food Engineering, vol. 65, no. 4, pp. 609-617, 2004.

[13] B. A. Souraki and D. Mowla, "Axial and radial moisture diffusivity in cylindrical fresh green beans in a fluidized bed dryer with energy carrier: modeling with and without shrinkage," Journal of Food Engineering, vol. 88, no. 1, pp. 9-19, 2008.

[14] L. Hassini, S. Azzouz, R. Peczalski, and A. Belghith, "Estimation of potato moisture diffusivity from convective drying kinetics with correction for shrinkage," Journal of Food Engineering, vol. 79, no. 1, pp. 47-56, 2007.

[15] J. Mitra, S. L. Shrivastava, and P. Srinivasa Rao, "Vacuum dehydration kinetics of onion slices," Food and Bioproducts Processing, vol. 89, no. 1, pp. 1-9, 2011.

[16] M. Vasić, Z. Radojević, and Ž. Grbavčić, "Calculation of the effective diffusion coefficient during the drying of clay samples," Journal of the Serbian Chemical Society, vol. 77, no. 4, pp. 523533, 2012.

[17] L. Mayor and A. M. Sereno, "Modelling shrinkage during convective drying of food materials: a review," Journal of Food Engineering, vol. 61, no. 3, pp. 373-386, 2004.

[18] W. Senadeera, B. G. Bhandari, and B. Wijesinghe, "Physical properties and fluidization behavior of fresh green bean particulates during fluidized bed drying," Food And Bioproducts Processing, vol. 78, pp. 43-47, 2000.

[19] A. Touil, S. Chemkhi, and F. Zagrouba, "Modelling of the drying kinetics of Opuntia ficus indica fruits and cladodes," International Journal of Food Engineering, vol. 6, no. 2, article 11, 2010.

[20] A. Touil, S. Chemkhi, and F. Zagrouba, "Physico-chemical characterisation of Opuntia dillenii fruit," International Journal of Food Engineering, vol. 6, no. 5, article 5, 2010.

[21] I. Dincer and S. Dost, "An analytical model for moisture diffusion in solid objects during drying," Drying Technology, vol. 13, no. 1-2, pp. 425-435, 1995.

[22] J. Crank, The Mathematics of Diffusion, Clarendon Press, London, UK, 2nd edition, 1975.

[23] N. P. Zogzas, Z. B. Maroulis, and D. Marinos-Kouris, "Effective moisture diffusivity estimation from drying data. A comparison between various methods of analysis," Drying Technology, vol. 14, no. 7-8, pp. 1543-1573, 1996.

[24] M. A. S. Barrozo, A. M. Souza, S. M. Costa, and V. V. Murata, "Simultaneous heat and mass transfer between air and soybean seeds in a concurrent moving bed," International Journal of Food Science and Technology, vol. 36, no. 4, pp. 393-399, 2001.

[25] S. Chemkhi and F. Zagrouba, "Characterisation of potato slices during drying: density, shrinkage, and thermodynamic of sorption," International Journal of Food Engineering, vol. 7, no. 3, article 8, 2011.

[26] M. Maskan, "Drying, shrinkage and rehydration characteristics of kiwifruits during hot air and microwave drying," Journal of Food Engineering, vol. 48, no. 2, pp. 177-182, 2001.

[27] D. Mihoubi, S. Timoumi, and F. Zagrouba, "Modelling of convective drying of carrot slices with IR heat source," Chemical Engineering and Processing, vol. 48, no. 3, pp. 808-815, 2009.

[28] A. Talla, J.-R. Puiggali, W. Jomaa, and Y. Jannot, "Shrinkage and density evolution during drying of tropical fruits: application to banana," Journal of Food Engineering, vol. 64, no. 1, pp. 103-109, 2004.

[29] M. E. Katekawa and M. A. Silva, "A review of drying models including shrinkage effects," Drying Technology, vol. 24, no. 1, pp. 5-20, 2006. 
[30] X. Xiong, G. Narsimhan, and M. R. Okos, "Effect of composition and pore structure on binding energy and effective diffusivity of moisture in porous food," Journal of Food Engineering, vol. 15, no. 3, pp. 187-208, 1992.

[31] S. Azzouz, A. Guizani, W. Jomaa, and A. Belghith, "Moisture diffusivity and drying kinetic equation of convective drying of grapes," Journal of Food Engineering, vol. 55, no. 4, pp. 323-330, 2002.

[32] S. Chemkhi and F. Zagrouba, "Water diffusion coefficient in clay material from drying data," Desalination, vol. 185, no. 1-3, pp. 491-498, 2005. 

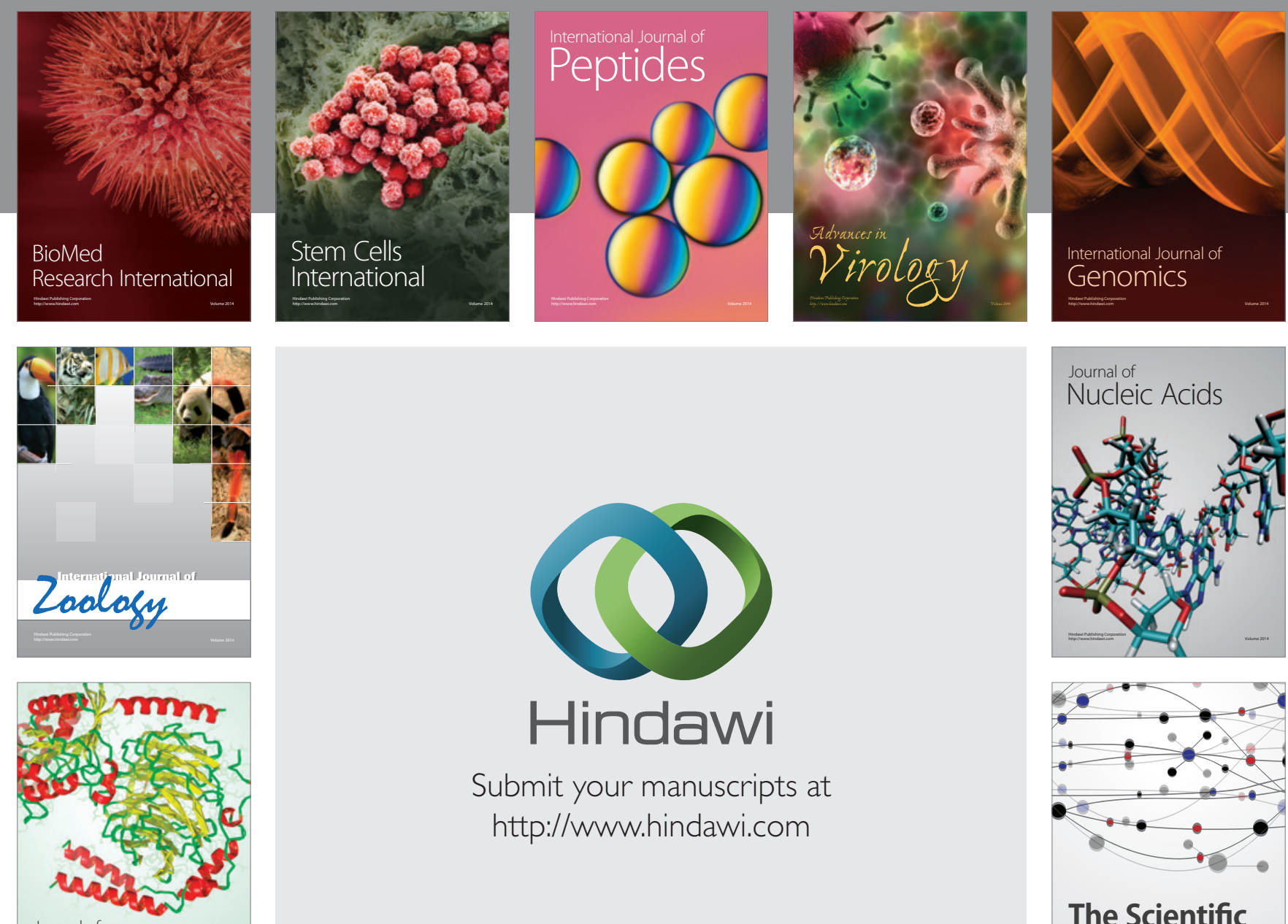

Submit your manuscripts at

http://www.hindawi.com

Journal of
Signal Transduction
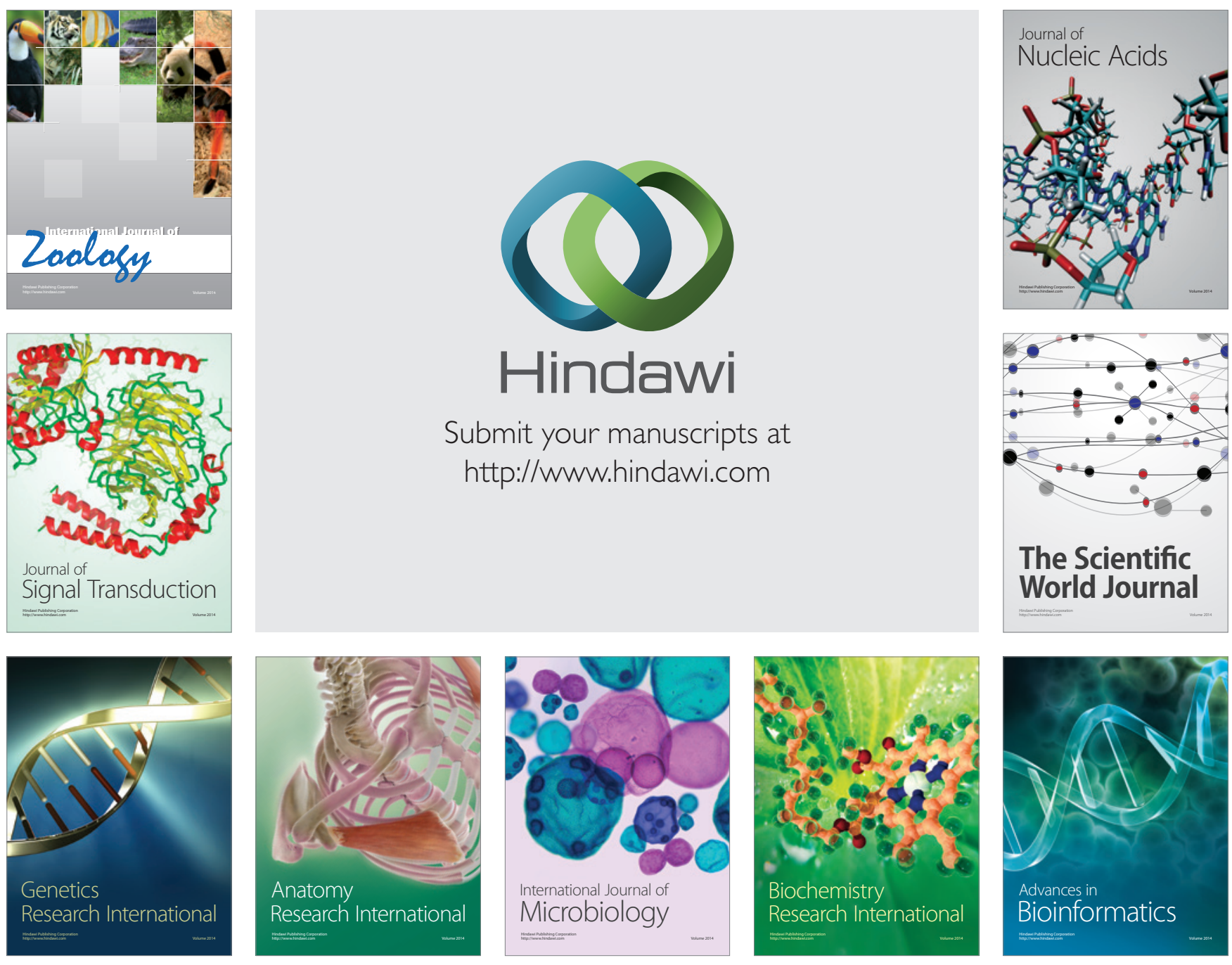

The Scientific World Journal
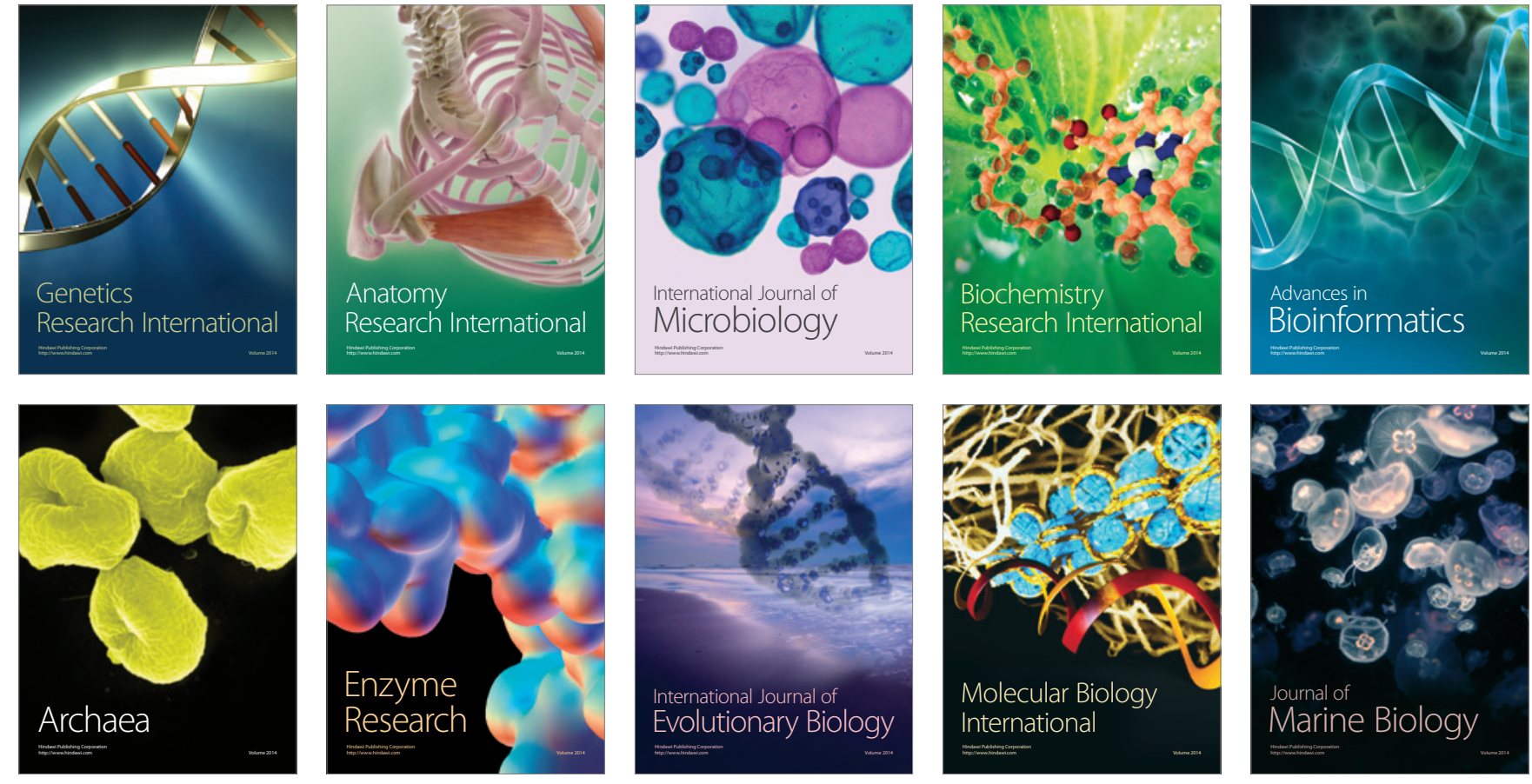